\title{
Introduction to Policies and Strategies for Digital Government Minitrack
}

\author{
Antonio Cordella \\ London School of Economics and \\ Political Science \\ a.cordella@1se.ac.uk
}

\author{
Frank Bannister \\ Trinity College, Dublin \\ Frank.Bannister@tcd.ie
}

\author{
Peter Parycek \\ Danube-University Krems \\ peter.parycek@donau-uni.ac.at
}

Following the minitrack tradition, this track called for multidisciplinary e-government contributions aimed at enhancing theoretical thinking about the challenges associated with the design, management and evaluation of the policies and strategies deployed to support, facilitate and promote digital government. The minitrack invited submissions that contributed to the analysis of the challenges faced by governments when formulating e-government policies. Specifically, the minitrack focuses on the effects of ICT implementations that are designed to transform government organisations, public sector management and the functioning of public institutions in general. We invited and encouraged the submission of case studies which demonstrate best practices in the design, management and evaluation of e-government policies and strategies.

This year the selected papers explore the increasing importance of e-governance and the challenges for governance associated with the adoption and use of information technology in public administration. The importance of collaboration and new forms of governance to the success of e-governance projects are the core issues discussed by two of the accepted papers.

The first of these papers discusses how citizens' participation initiatives enable public decision-makers to integrate the knowledge and preferences of citizens into municipal planning processes at an early stage. The research focus is on the use of workshops to foster the collaboration of citizens and public authorities. In recent years e-participation has evolved as a strategic pillar in digital governance, but has not yet resulted in the widespread use of participation workshops. Establishing an integrated e-participation approach that combines traditional and e-participation instruments poses a practical challenge. The paper applies Collaboration Engineering to design and evaluate an eparticipation workshop process that incorporates theoretical and practical requirements to allow for the seamless transfer of digitally generated input across instruments and process steps, and to sustain a workshop execution by domain-specific practitioners. Evaluation results suggest promising potentials of the developed process design for increased idea elaboration and more effective documentation of workshop-based participation.

The second paper seeks to enhance understanding regarding the public sector stewardship of integrated services delivery initiatives in joined-up digital government It focuses on understanding the nature of the steward's role, the skills required of those performing stewardship, and the key challenges stewards face. The paper uses a study of New Zealand public sector in order to understand both the practice and the perception of the stewardship concept. Three tiers of stewardship practice are identified: (1) Internal Stewardship, (2) Inter-Agency Stewardship, and (3) Stewardship as a Governance Model. Each tier has its own challenges. The paper concludes that in order to overcome these challenges stewards need to perform two complementary sub-roles: Navigator and Storyteller. Understanding the operational challenges of the stewardship tiers and how the stewardship roles are enacted has implications for both practitioners and researchers.

The third paper sets out to provide better conceptual clarity on open data users by connecting an empirical analysis of policy documents to emerging theoretical research on data publics. A content analysis of United States federal policy documents identifies the language used to represent people who might reuse data. An inductive qualitative analysis of mandated digital strategy reports generated a taxonomy that characterizes people mentioned in open data policy. In addition to the taxonomy, this research contributes a set of propositions that can be used to predict data reuse based on these characteristics. The results encourage further dialogue between the public sphere and digital government scholars with a view to coming up with testable explanations about data publics.

The fourth paper highlights that while federalism and e-government are important to many countries across the globe, in Germany two contradictory characteristics that are particularly relevant. First, citizens and businesses want to receive e-government services in an accessible and seamless manner, but the identification of government entities that are responsible for specific 
service delivery in federal states can be difficult. Second, while national e-government has to react to fast developments, decision-making is distributed and is rather slow in the states themselves. To address the area of tension between federalism and e-government, the paper suggests seven polices that raise the internal efficiency and the external simplicity of federalism in Germany. These policies are then evaluated in semistructured interviews with eleven leaders from the
German government. The evaluation reveals the appropriateness of the policies to address the problem of federalism in e-government.

The minitrack chairs are grateful for the authors' contributions and hope that our readers will enjoy the insights and the contribution to our understanding of the importance of policies and strategies in egovernment deployments that these papers provide. 